Canadian Oncology

Nursing Journal

Revue canadienne

de soins infirmiers

en oncologie

Volume 28, Issue 2 • Spring 2018

elSSN: 2368-8076 


\title{
Mobilizing purpose and passion in oncology nursing care of older adults: From conference workshop to special interest group
}

\author{
by Fay J. Strohschein and Lorelei J. Newton
}

\begin{abstract}
In Canada, $45 \%$ of new cancer cases and 63\% of cancer deaths occur amongst Canadians 70 years and older. These older people with cancer and their families present particular needs and concerns that often remain under-recognized and unmet. As the number of older Canadians is expected to more than double in the next 25 years, we must integrate understanding of aging into oncology nursing practice, education, policy, and research, developing models of care that optimize appropriate outcomes for older adults.

We present the Canadian Association of Nurses in Oncology (CANO) Oncology and Aging Special Interest Group (SIG), as an initiative to mobilize oncology nurses in addressing these concerns. In an overview of the 2015 CANO conference workshop that launched this group, we highlight practice concerns and priorities identified through interactive discussion with participants. We also describe development of the SIG since 2015, including objectives that will define next steps.
\end{abstract}

\section{INTRODUCTION}

$\mathrm{T}$ The impact of our aging Canadian population on the provision of healthcare is increasingly evident, particularly within cancer care. It is estimated that $45 \%$ of new cancer cases, and $63 \%$ of cancer deaths will occur among Canadians 70 years and older, with the majority of the most common cancers (lung, colorectal) occurring in these older adults (Canadian Cancer Society's Advisory Committee on Cancer Statistics, 2017). Age-based disparities in mortality rates (Canadian Cancer Society's Advisory Committee on Cancer Statistics, 2017), a widening age-gradient in survival (Brenner \& Arndt, 2004), unmet needs (Puts, Papoutsis, Springall, \& Tourangeau, 2012) and patterns of sub-optimal treatment even when health and functional status are considered (Bojer \&

\section{ABOUT THE AUTHORS}

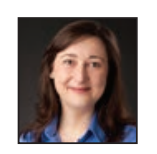

Fay J. Strohschein, RN, PhD(c) (Corresponding Author),

Doctoral Candidate, Ingram School of Nursing, McGill University/

Nursing Counsellor, Oncology \& Aging Program, Segal Cancer

Centre, Jewish General Hospital, 3755 Côte-Sainte-Catherine Rd, Montreal, QC H3T 1E2

Email: fay.strohschein@mail.mcgill.ca

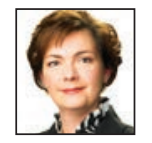

Lorelei J. Newton, RN, PhD, Faculty, Nursing, Health \& Human Services, Camosun College, 3100 Foul Bay Road, Victoria, BC V8P 5J2

Email: NewtonL@camosun.ca

DOI:10.5737/236880762828994
Roikjær, 2015; Hamaker et al., 2015), suggest clear gaps in how we are addressing age-related concerns in cancer care.

As oncology nurses, we are uniquely positioned to integrate understanding of biopsychosocial aspects of aging into cancer care. Although working with older people may constitute a sizeable proportion of our practice, we often have little training or access to resources in geriatrics. Are we addressing issues and concerns related to aging or simply providing cancer care to people who happen to be in this age group? Given that the number of older adults in our population is expected to more than double in the next 25 years (Statistics Canada, 2014), with a corresponding increase in new cancer cases (Canadian Cancer Society's Advisory Committee on Cancer Statistics, 2015), we need to ensure that we have the necessary knowledge, skills, and resources in place to address the needs of older patients with cancer and those close to them.

To begin discussing how we, as oncology nurses, can strengthen the care of older people with cancer, we held a workshop at the Canadian Association of Nurses in Oncology (CANO) annual conference in October 2015. From this workshop, we launched the CANO Oncology and Aging Special Interest Group (SIG). In this article, we share an overview of this workshop and initial SIG development.

Our structure follows the 2015 CANO conference theme of People, Purpose, Passion, adding a final focus on Progress. We begin with an overview of our workshop presentation, highlighting salient concerns related to the care of older people with cancer and the purpose of geriatric oncology as a sub-specialty. We then provide a summary of the workshop discussion, within which participants' passion in identifying and addressing age-related concerns for their patients became evident. Participants agreed on the value of developing a SIG and discussed SIG priorities. We then discussed the progress that we are making as an SIG, underscoring the purpose and objectives that are defining next steps.

\section{PEOPLE: IDENTIFYING UNIQUE CONCERNS IN CARING FOR OLDER ADULTS WITH CANCER}

There is great variation in the ways older adults experience cancer and related treatment. These experiences are shaped by heterogeneity in terms of the biological, psychological and social aspects of aging. This heterogeneity in aging is evident not only when comparing different individuals, but also when comparing different generations (Gubrium \& Charmaz, 1992), and when comparing different organ systems within an individual (White \& Cohen, 2006). 
When thinking about the geriatric population, we may visualize frail, elderly people. However, these are only a small subset of older adults receiving treatment for cancer (Retornaz et al., 2008). For example, the average life expectancy of an 80-year-old woman may range from 13.0 years for those in the highest 25th percentile, to 4.6 years for those in the lowest (Walter \& Covinsky, 2001): one may be wheelchair-bound and require assistance with activities of daily living, the other may be living alone, exercising daily, and engaging actively in community work. Thus, chronological age is a poor indicator of the age-related concerns a person may be experiencing. Instead of defining older by the number of years that a person has lived, we, in cancer care, must consider functional age (Klepin, Rodin, \& Hurria, 2015) or physiological age (National Cancer Institute, 2010), striving for awareness of issues associated with aging that may occur for different people at different times.

Cancer pathology changes with age, with some cancers becoming more aggressive while others become more indolent (White \& Cohen, 2006). Other important normal and abnormal physiological changes occur with age, such as decreased homeostatic reserve and adaptability. The extent of these changes is not always predictable, and can have a profound effect on treatment efficacy and patients' ability to adhere to a treatment regimen (Sawhney, Sehl, \& Naeim, 2005; Sehl, Sawhney, \& Naeim, 2005). Physiological changes may also lead to mobility, sensory, cognitive impairments, and/or multiple morbidity, key risk factors for geriatric syndromes such as functional decline, polypharmacy, falls, delirium, incontinence, weight loss, and depression (Inouye, Studenski, Tinetti, \& Kuchel, 2007; Olde Rikkert, Rigaud, van Hoeyweghen, \& de Graaf, 2003). Variation in a person's social situation may cause them to be more or less susceptible to risk (Andrew \& Keefe, 2014), highlighting the need to understand patient perspectives and personalize care to each person's situation.

Lack of awareness of heterogeneity and issues associated with aging leads to ageism: stereotypes of decline or predetermined judgements of 'successful aging.' Ageism is insidious in healthcare (Alliance for Aging Research, 2003), and oncology is no exception (Kagan, 2008; Wedding \& Stauder, 2014). Though we may guard against its more overt forms, its subtler forms are often overlooked. Examples include inappropriate presentation of information, inaccessibility of healthcare environments, lack of coordination of care, limited resources to ensure older patients' access to screening and treatment, and variation in clinical management based on the values and perceptions of the cancer care team (Tariman, 2009; Tariman, Berry, Cochrane, Doorenbos, \& Schepp, 2012). Perpetuating these patterns of ageism is a dearth of supporting research, due, in part, to lack of inclusion in clinical trials and lack of outcome measures reflecting end points of importance to older people (Hurria et al., 2014; Hurria et al., 2015; Sinding $\&$ Wiernikowski, 2009). These issues must be addressed to inform appropriate treatment and ensure that older adults receive the care they need.

\section{PURPOSE: UNDERSTANDING THE ROLE OF GERIATRIC ONCOLOGY}

Geriatric oncology is a growing sub-specialty that integrates understanding of aging and oncology to provide optimal and appropriate care for older people with cancer and those close to them. It is a relatively young discipline. Bias in treatment of older adults was first recognized in the mid-1970s to 1980 s, and, after a period of advocacy, purposeful progress in the field first began in the mid-1990s (Boyle, 2006). The Oncology Nursing Society released its first position statement on oncology nursing and geriatric oncology in 1992 (Boyle et al., 1992), which was subsequently updated with the Geriatric Oncology Consortium (Oncology Nursing Society \& Geriatric Oncology Consortium, 2004, 2007). This statement highlights the lack of research and the complexities of care that are evidenced in disparities and patterns of under-treatment impacting quality of life. The recent Institute of Medicine report on Quality Cancer Care highlights the need for collaboration between primary, geriatric, and specialist care teams (Institute of Medicine, 2013), with collaboration between oncology and geriatric nursing being a key component of this goal (Ferrell, McCabe, \& Levit, 2013).

Geriatric oncology calls for interdisciplinary and inter-professional collaboration to ensure appropriate care. Many older adults who walk through the doors of cancer care centres appear well, fit, and independent. However, they may have vulnerabilities to treatment toxicities, complications, or side effects that are not evident in initial interactions with the treating team. Comprehensive geriatric assessment provides a means of assessing older patients' baseline strengths and vulnerabilities, evaluating functional status, uncovering hidden vulnerabilities to treatment side effects, complications, and toxicities (National Comprehensive Cancer Network, 2016; Wildiers et al., 2014). As the medical community mobilizes to support development and growth of the geriatric oncology sub-specialty in research, education, practice, and policy development, the nursing community must also mobilize to support the same development within our own profession. We must consider both the competencies related to aging that are needed to deliver effective oncology nursing care, while also supporting the development of nurses practising specifically within the subspecialty of geriatric oncology.

\section{PASSION: SHARING CHALLENGES AND CONCERNS IN ONCOLOGY NURSING CARE FOR OLDER ADULTS}

Finding a common interest in these challenges and concerns related to oncology and aging, we (the authors) identified a need to engage in discussion with other oncology nurses. To begin this discussion, and explore the possibility of a special interest group, we conducted a workshop for the 2015 CANO conference. This workshop was open to all conference attendees. Bringing our unique perspectives (FS then as clinical nurse specialist/nurse navigator for senior oncology patients at the Segal Cancer Center in Montreal, LN then as 


\begin{tabular}{|c|c|c|}
\hline Ageism & $\begin{array}{l}\text { Focusing on chronological age, without consideration of } \\
\text { performance status and comorbidities } \\
\text { Viewing aging as a comorbidity, rather than as a developmental } \\
\text { stage } \\
\text { Viewing older adults as second-class citizens } \\
\text { Lacking access to comprehensive geriatric assessment for all } \\
\text { patients } \\
\text { Failing to recognize that next generation may be different }\end{array}$ & $\begin{array}{l}\text { Develop links with geriatrics to facilitate comprehensive assessment, } \\
\text { identifying heterogeneity and needs associated with aging } \\
\text { Do research to support the involvement of geriatric practitioners } \\
\text { Establish access to a specialist nurse in geriatrics, e.g., Clinical Nurse } \\
\text { Specialist in geriatrics } \\
\text { Integrate processes to prioritize older patients for comprehensive } \\
\text { geriatric assessment } \\
\text { Develop tools to support older adults who don't require or don't have } \\
\text { access to a full comprehensive geriatric assessment } \\
\text { Bring a gerontologic lens to care, of which palliative care is one piece }\end{array}$ \\
\hline
\end{tabular}

Practice Leader with the British Columbia Cancer Agency in Victoria), we designed the workshop with three objectives:

- Provide an overview of the ways in which oncology and aging intersect, considering age-related needs and concerns that are often under-recognized and understudied.

- Highlight the purpose of geriatric oncology, as a sub-specialty.

- Facilitate an interactive discussion with workshop participants to explore challenges and successes in caring for older adults with cancer, and consider SIG development.

We welcomed the participation of 12 colleagues working in various clinical settings across Canada. We began to explore challenges and successes in caring for older adults with cancer. The poignant stories that participants shared concerning the complexity of caring for older adults throughout the cancer trajectory revealed a passion for addressing concerns and challenges facing these older patients, as well as the moral distress that oncology nurses feel when resources and systems are not in place to appropriately address these issues.
This moral distress was particularly evident as stories of both overly-aggressive treatment and under-treatment were threaded through the conversation. Many questions arose. Although the majority of older adults are generally in good health when they start treatment, how do we leave them? Do we support them in returning to their baseline level of function? Do we even know what their baseline level of function was? What would it look like to integrate a gerontologic approach to our nursing assessments and interventions along the full trajectory of care? How and when do we appropriately refer older adults to palliative care? We also moved to a consideration of systems issues, discussing the explicit and implicit decisions surrounding access and rationing of treatment for all cancer patients, and how patient age may be implicated in these decisions.

Through our discussion, we uncovered many clinical concerns related to the provision of oncology nursing for older adults. Participants expressed concerns in three domains: 
ageism; sub-optimal treatment outcomes; as well as ethical issues concerning treatment and care decisions (Table 1). Many of the concerns identified were based on what participants heard and saw in their discussions and interactions with patients. Within each domain, attendees not only expressed specific concerns, but also identified objectives and ideas of how the cancer care system could act in response to these concerns.

The list in Table 1 highlights oncology nurses' sensitivity to issues related to aging and awareness of the system changes that are necessary to address these needs. Workshop attendees also recognized the ways in which the social determinants of health, such as income, education, social exclusion, gender, and race, interact with the issues identified, impacting resources and raising the level of concern or need. This interaction was identified as being particularly salient in certain cancer populations, such as those with head and neck cancer or multiple myeloma, and those living in rural locations.

As noted above, our discussion revealed that the gap between the identified needs of older people affected by cancer and the necessary system response was the source of moral distress for workshop participants. We recognized that ageism does not only impact older patients directly, with respect to

\section{Table 2: Participant-Identified Priorities for a Special Interest} Group (SIG)

\begin{tabular}{|l|l|}
\hline Priorities & Specific Ideas \\
\hline Promote & $\begin{array}{l}\text { Inform oncology nurses about what is facing } \\
\text { us, in terms of: } \\
\text { crucial first step } \\
\text { expected increases in the numbers of } \\
\text { older Canadians experiencing cancer, and } \\
\text { - Potential challenges this will bring to our } \\
\text { provision of care. } \\
\text { - Strengthen awareness concerning the } \\
\text { challenges associated with aging that } \\
\text { impact cancer care for patients and family } \\
\text { members. }\end{array}$ \\
\hline $\begin{array}{l}\text { Develop tools to } \\
\text { engage members } \\
\text { and support SIG } \\
\text { growth }\end{array}$ & $\begin{array}{l}\text { - Creation of a webpage of resources } \\
\text { Listserv for members }\end{array}$ \\
\hline $\begin{array}{l}\text { Advance practice } \\
\text { by identifying a } \\
\text { tangible project to } \\
\text { work on together }\end{array}$ & $\begin{array}{l}\text { - Survey CANO members concerning needs } \\
\text { relating to the care of older adults } \\
\text { tool for oncology nurses that would: } \\
\text { - Promote screening for comprehensive } \\
\text { geriatric assessment, } \\
\text { - Support identification of cognitive/ } \\
\text { sensory deficits that may impact } \\
\text { communication, and } \\
\text { - Recognize patient/family values, priorities, } \\
\text { goals, and strengths. }\end{array}$ \\
\hline
\end{tabular}

their access to optimal and appropriate treatment and care, but also indirectly, by hampering our ability to mobilize system change for these patients and their family members. This is an important source of frustration. We must work together to develop the resources, tools, skills, and knowledge to address these needs on the level of education, practice, research, and policy.

The group recognized that a crucial first step in moving towards these goals would be raising awareness and visibility of these concerns within CANO, and bringing together nurses with a shared interest in the care of older adults with cancer. Thus, we agreed that implementing an oncology and aging SIG within CANO would be a valuable way to initiate this collaborative work, supporting the CANO strategic plan and allowing us to make use of tools and resources provided by CANO. Our workshop ended with a discussion regarding initial priorities for a SIG, which are summarized in Table 2.

Table 3: Oncology and Aging Special Interest Group Purpose and Objectives

Purpose: To create a national forum for nurses who have a common interest in the care of older people with cancer, engaging in Canada-wide activities that promote innovation in practice, research, education, leadership, and policy development.

Aim: Integrate understanding of oncology and aging to support optimal care for older people with cancer and those close to them.

\section{Objectives:}

Promoting awareness

- Advocate for the optimal care of older adults with cancer and those close to them, drawing awareness to their unique strengths, needs, and concerns within CANO initiatives and beyond.

- Highlight the critical role of nurses in optimizing the care of older adults with cancer, and those close to them, within interprofessional and interdisciplinary care teams.

Engaging members

- Identify, develop, and share tools and resources that support knowledge and skill in caring for older adults with cancer and those close to them.

Advancing practice

- Initiate projects to strengthen the care of older adults with cancer and those close to them, driven by issues, needs, and trends identified by our members.

- Promote Geriatric Oncology Nursing as a sub-specialty that strives to integrate expertise in cancer care and geriatrics, developing CANO standards and competencies for this sub-specialty.

Enabling collaboration

- Collaborate with other national and international organizations that strive to strengthen the care of older adults with cancer. 


\section{PROGRESS: IDENTIFYING OBJECTIVES AND PRIORITIES IN SIG DEVELOPMENT}

The 2015 workshop lent clear support for the development of a CANO Oncology and Aging SIG. The SIG was established in December 2015. Our first annual meeting at the 2016 CANO annual conference extended the discussion of SIG priorities, identifying a need to increase conference programming relating to the care of older adults, develop webinars and/or workshops to provide information concerning tools and resources to inform oncology nursing care of older adults and their families, and articulate the role of oncology nurses in the clinical assessment of older adults with cancer and their families. This discussion has continued in subsequent meetings, as we work to define next steps and our overall strategic plan. Based on these discussions, and according to the priorities identified by workshop participants and SIG members, we articulated the purpose, aim, and objectives for the Oncology and Aging SIG, which we present in Table 3. The initial purpose and objectives were approved by SIG members in May 2017.

To support our initial objectives and priorities, we have developed a website for SIG members within the CANO web platform, providing access to shared resources and a group feed, to which members can post comments or questions to all members. We are collaborating on conference and webinar presentations to raise awareness within CANO. We are also working to develop relationships with national and international organizations supporting the care of older adults with cancer, including the Canadian Gerontological Nursing Association, the Canadian Network on Aging and Cancer, and the Nursing/Allied Health Special Interest Group of the International Society of Geriatric Oncology. As of December 2017, we had 99 members from across Canada and the United States, representing diverse areas of clinical practice including staff nurses, nurse clinicians, nurse navigators, educators, research coordinators, advanced practice nurses, nurse scientists, educators, and students.

\section{REFERENCES}

Alliance for Aging Research. (2003). Ageism: How healthcare fails the elderly. Washington, DC. Retrieved from https://www. agingresearch.org/pressrooms/view/51\#.WbwXfLpFyhI

Andrew, M.K., \& Keefe, J.M. (2014). Social vulnerability from a social ecology perspective: a cohort study of older adults from the National Population Health Survey of Canada. BMC Geriatrics, 14(1), 90. doi:10.1186/1471-2318-14-90

Bojer, A.S., \& Roikjær, O. (2015). Elderly patients with colorectal cancer are oncologically undertreated. European Journal of Surgical Oncology, 41(3), 421-425. doi:10.1016/j.ejso.2014.10.065

Boyle, D.A. (2006). A review of the evidence base of an evolving science: Gero-oncology nursing. In H.B. Muss, C.P. Hunter \& K.A. Johnson (Eds.), Treatment and management of cancer in the elderly (pp. 507-538). New York: Taylor \& Francis Group.

Boyle, D.M., Engelking, C., Blesch, K.S., Dodge, J., Sarna, L., \& Weinrich, S. (1992). Oncology Nursing Society position paper on cancer and aging: The mandate for oncology nursing. Oncology Nursing Forum, 19(6), 913-933.

Brenner, H., \& Arndt, V. (2004). Recent increase in cancer survival according to age: Higher survival in all age groups, but widening age gradient. Cancer Causes a Control, 15(9), 903-910. doi:10.2307/3553599

\section{CONCLUSION}

Integrating understanding of aging into cancer care is becoming a critical concern for oncology nurses. This workshop highlighted oncology nurses' sensitivity to, and concern about the quality of care provided to their older patients. Participants drew attention to the ways in which oncology nurses can work to confront ageism by acknowledging heterogeneity and age-related concerns, optimizing treatment outcomes by ensuring necessary support and resources, and addressing ethical issues related to treatment decision-making by advocating for appropriate treatment and decision support. Engaging with participants confirmed the value of, and need for developing an Oncology and Aging SIG, and gave direction for initial goals and priorities. Future directions will include development of our strategic plan, integrating the perspectives of older adults with cancer and those close to them.

By developing the CANO Oncology and Aging SIG, we hope to contribute to the ongoing development of a model of cancer care that supports this integration, both by equipping oncology nurses in their care of older adults and by supporting the development of nurses specializing in geriatric oncology care. In the context of this SIG, we aim to draw attention to the unique strengths, needs, and concerns of older adults with cancer and those close to them, creating a national forum to promote innovation in their care.

\section{ACKNOWLEDGEMENTS}

We would like to thank the 2015 CANO Conference Oncology and Aging workshop participants for their active engagement and thoughtful insight, which formed the foundations of this work. We would also like to acknowledge those who have participated in the subsequent SIG meetings for their invaluable contributions in shaping the priorities, objectives, and activities of the group.

Canadian Cancer Society's Advisory Committee on Cancer Statistics (2015). Canadian Cancer Statistics 2015. Toronto, ON: Canadian Cancer Society.

Canadian Cancer Society's Advisory Committee on Cancer Statistics (2017). Canadian Cancer Statistics 2017. Toronto, ON: Canadian Cancer Society.

Ferrell, B., McCabe, M.S., \& Levit, L. (2013). The Institute of Medicine report on high-quality cancer care: Implications for oncology nursing. Oncology Nursing Forum, 40(6), 603-609. doi:10.1188/13. onf.603-609

Gubrium, J.F., \& Charmaz, K. (1992). Introduction. In J.F. Gubrium \& K. Charmaz (Eds.), Aging, self, and community: A collection of readings (pp. ix-x). Greenwich, Connecticut: Jai Press.

Hamaker, M.E., van Rixtel, B., Thunnissen, P., Oberndorff, A.H., Smakman, N., \& ten Bokkel Huinink, D. (2015). Multidisciplinary decision-making on chemotherapy for colorectal cancer: An agebased comparison. Journal of Geriatric Oncology, 6(3), 225-232. doi:10.1016/j.jgo.2015.01.002

Hurria, A., Dale, W., Mooney, M., Rowland, J.H., Ballman, K.V., Cohen, H.J., ... Mohile, S.G. (2014). Designing therapeutic clinical trials for older and frail adults with cancer: U13 conference 
recommendations. Journal of Clinical Oncolog $\gamma, 32(24), 2587-2594$. doi:10.1200/JCO.2013.55.0418

Hurria, A., Levit, L.A., Dale, W., Mohile, S.G., Muss, H.B., Fehrenbacher, L., ... Cohen, H.J. (2015). Improving the evidence base for treating older adults with cancer: American Society of Clinical Oncology Statement. Journal of Clinical Oncology, 33(32), 3826-3833. doi:10.1200/jco.2015.63.0319

Inouye, S.K., Studenski, S., Tinetti, M.E., \& Kuchel, G.A. (2007). Geriatric syndromes: Clinical, research, and policy implications of a core geriatric concept. Journal of the American Geriatrics Society, 55(5), 780-791. doi:10.1111/j.1532-5415.2007.01156.x

Institute of Medicine (2013). Delivering high-quality cancer care: Charting a new course for a system in crisis. Washington, DC: The National Academies Press.

Kagan, S.H. (2008). Ageism in cancer care. Seminars in Oncology Nursing, 24(4), 246-253. doi:10.1016/j.soncn.2008.08.004

Klepin, H.D., Rodin, M., \& Hurria, A. (2015). Treating older adults with cancer: Geriatric perspectives. In D.S. Dizon (Ed.), 2015 American Society of Clinical Oncology Educational Book. Alexandria, VA: American Society of Clinical Oncology.

National Cancer Institute (2010). Focusing on older cancer patients: A clinical need and a research necessity. Retrieved from https://www. cancer.gov/about-cancer/treatment/research/older-patients

National Comprehensive Cancer Network (2016). The NCCN Clinical Practice Guidelines in Oncology (NCCN Guidelines ${ }^{\mathrm{TM}}$ ) Older Adult Oncology (Version 2.2015). Retrieved from http://www.nccn.org/ professionals/physician_gls/pdf/senior.pdf

Olde Rikkert, M.G., Rigaud, A.S., van Hoeyweghen, R.J., \& de Graaf, J. (2003). Geriatric syndromes: Medical misnomer or progress in geriatrics? Netherlands Journal of Medicine, 61(3), 83-87.

Oncology Nursing Society, \& Geriatric Oncology Consortium (2004). Oncology Nursing Society and Geriatric Oncology Consortium joint position on cancer care in the older adult. European Journal of Cancer Care, 13(5), 434-435.

Oncology Nursing Society, \& Geriatric Oncology Consortium (2007). Oncology Nursing Society and Geriatric Oncology Consortium joint position on cancer care for older adults. [Practice Guideline]. Oncology Nursing Forum, 34(3), 623-624.

Puts, M.T., Papoutsis, A., Springall, E., \& Tourangeau, A.E. (2012). A systematic review of unmet needs of newly diagnosed older cancer patients undergoing active cancer treatment. Supportive Care in Cancer, 20(7), 1377-1394. doi:10.1007/s00520-012-1450-7
Retornaz, F., Monette, J., Batist, G., Monette, M., Sourial, N., Small, D., ... Bergman, H. (2008). Usefulness of frailty markers in the assessment of the health and functional status of older cancer patients referred for chemotherapy: A pilot study. Journals of Gerontology Series A-Biological Sciences \& Medical Sciences, 63(5), 518-522.

Sawhney, R., Sehl, M., \& Naeim, A. (2005). Physiologic aspects of aging: Impact on cancer management and decision making, Part I. Cancer Journal, 11(6), 449-460.

Sehl, M., Sawhney, R., \& Naeim, A. (2005). Physiologic aspects of aging: Impact on cancer management and decision making, Part II. Cancer Journal, 11(6), 461-473.

Sinding, C., \& Wiernikowski, J. (2009). Treatment decision making and its discontents. Social Work in Health Care, 48(6), 614-634. doi:10.1080/00981380902831303

Statistics Canada (2014). Table 052-0005: Projected population, by projection scenario, age and sex, as of July 1, Canada, provinces and territories, annual (persons). CANSIM [Database]. Retrieved from http://www5.statcan.gc.ca/cansim

Tariman, J.D. (2009). Half of patients with cancer are older than 65: Do you know how to care for older adults? ONS Connect, 24(12), 8-11.

Tariman, J.D., Berry, D., Cochrane, B., Doorenbos, A., \& Schepp, K. (2012). Physician, patient, and contextual factors affecting treatment decisions in older adults with cancer and models of decision making: A literature review. Oncology Nursing Forum, 39(1), E70-E83. doi:10.1188/12.ONF.E70-E83

Walter, L.C., \& Covinsky, K.E. (2001). Cancer screening in elderly patients. JAMA: The Journal of the American Medical Association, 285(21), 2750-2756.

Wedding, U., \& Stauder, R. (2014). Cancer and ageism. ecancer, 8, 39. doi:10.3332/ecancer.2014.ed39

White, H.K., \& Cohen, H.J. (2006). The older cancer patient. Medical Clinics of North America, 90(5), 967-982. doi:10.1016/j. mcna.2006.05.017

Wildiers, H., Heeren, P., Puts, M., Topinkova, E., Janssen-Heijnen, M.L.G., Extermann, M., ... Hurria, A. (2014). International Society of Geriatric Oncology consensus on geriatric assessment in older patients with cancer. Journal of Clinical Oncology, 32(24), 25952603. doi:10.1200/jco.2013.54.8347 